\title{
Corrigendum
}

\section{A Profile of Regulated Nurses Employed in Canadian Long-Term Care Facilities- CORRIGENDUM}

Janet E. Squires, Jennifer Baumbusch, Melissa Demery Varin, Ibo MacDonald, Stephanie Chamberlain, Anne-Marie Boström, Genevieve Thompson, Greta Cummings, and Carole A. Estabrooks

doi:10.1017/S0714980818000478. Published by Cambridge University Press, 12 March 2019

Anne-Marie Boström's name was misspelled in the original online version of the article by Squires et al. (2019). It has been corrected above and in the original version, both online and in print.

\section{Reference}

Squires, J. E., Baumbusch, J., Varin, M. D., MacDonald, I., Chamberlain, S., Boström, A-M., ... Estabrooks, C.A. (2019). A profile of regulated nurses employed in Canadian long-term care facilities. Canadian Journal on Aging, 38(2), 130-142. 